\title{
Use of bones taken from the operated areas of impacted third molars as autografts for implant placement: cases report
}

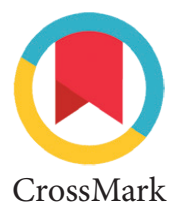

\author{
Antonius SS. Putra, Robby Ramadhonie, Poerwati S. Rahajoe*
}

\begin{abstract}
Objective: This report aims to explain how the bones taken from the operated areas of impacted third molars are used as autografts for implant placement.

Methods: Two patients with missing maxillary incisor, lack of alveolar bone support and impacted third molar underwent an implant placement procedure with bone grafting and third molar removal, subsequently. In both cases, the implant was placed and resulted in a dehiscence-typed defect. The defect was filled with an autograft harvested from the operated area of impacted third molar, and then covered with PRF membrane and titanium mesh. The wound was
\end{abstract}

sutured accordingly and evaluation was taken 3 months following the procedure.

Results: Under direct observation, in both cases, new bone formation appeared in the buccal region of the implant to the margin of the implant crestal. The implant was stable and no complications occurred.

Conclusion: On the basis of this finding, it can be concluded that operated area of impacted third molar can be considered as an ideal alternative for donor sites for patients who needed bone grafts and third molar extraction simultaneously.
Department of Oral and Maxillofacial Surgery, Faculty of Dentistry, Gadjah Mada University, Yogyakarta, Indonesia

\section{*Corresponding to:}

Poerwati S. Rahajoe, Oral and Maxillofacial Surgeon, Department of Oral and Maxillofacial Surgery, Faculty of Dentistry, Gadjah Mada University, Yogyakarta, Indonesia poerwati_soetji_fkg@ugm.ac.id

Received: 7 June 2018

Revised: 7 June 2018

Accepted: 23 July 2018 A

vailable online 1 December 2018

Keywords: Autograft, Bone augmentation, Implant, Impacted teeth, Third molar extraction

Cite this Article: Putra ASS, Ramadhonie R, Rahajoe PS. 2018. Use of bones taken from the operated areas of impacted third molars as autografts for implant placement: cases report. Journal of Dentomaxillofacial Science 3(3): 192-195. D0I: 10.15562/jdmfs.v3i3.745

\section{Introduction}

Implants have been widely used to support dental crowns and have numerous advantages over conventional dentures. In addition to keeping the alveolar bone thickness, facilitating phonetic functions and better occlusion, implants are also aesthetic, comfortable, stable and permanent with no need for manipulating adjacent teeth and therefore, provide optimal psychological effects. To obtain an ideal result, proper pre-operative planning is deemed necessary. ${ }^{1}$

One of the most common problems in pre-operative planning is the lack of bone support for implant placement. ${ }^{2}$ Atrophy of the alveolar bone is common, especially in post-traumatic dentoalveolar patients such as dental avulsion. The bone walls of the buccal section are generally broken or detached with the tooth. ${ }^{3}$ Bone deficits in vertical and/or horizontal dimensions will prevent from an ideal implant placement. Therefore it is necessary to perform graft-supported bone augmentation. ${ }^{4}$

Types of grafts include allograft, alloplastic, xenograft, and autograft, among which the last type remains the best choice because of its osteoinduction and osteoconduction ability. Autograft can be harvested as particles or blocks, from different areas of the body in limited quantities to fit the needs and defect size. Low quantity of autograft can be obtained from intraoral donor areas, such as maxillary tuberosity, ascending ramus, torus, exostosis, bone from implant site preparation and mandibular symphysis. ${ }^{1,5}$

The fact that autograft harvest requires two operated areas, one for the autograft source site and the other one for the recipient site, has become the major drawback of autografts. ${ }^{5}$ The procedures for surgical removal of impacted third molars are common to perform, serving as prophylactic or therapeutic efforts. Prophylactic efforts are done when the impacted teeth are improperly positioned and likely to cause problems such as pericoronitis, dentigerous cysts, caries, and others. Surgical removal of impacted third molars consistently requires bone reduction to free the impacted teeth. ${ }^{6}$ The reduced bones are mostly discarded and unused while the bones are by nature healthy cortical bones that may function as a potential source of autografts in a limited number.

This case report describes the successful use of autografts taken from the operated areas of impacted third molars for implant placement. With this treatment, patients are likely to receive the best therapy based on the latest scientific evidence with the lowest rate of morbidity. 


\section{Case Report Case 1}

A 21 years old woman came to the emergency room of Prof. Soedomo Dental and Oral Hospital Yogyakarta with the chief complaints of missing and broken upper front teeth following a single motorcycle accident 2 hours previously figure 1 . Her condition was as follows: good general consciousness, compos mentis, GCS (Glasgow Coma Scale) 15 no sign of head injury and vital signs within normal limits. Further, her face appeared asymmetric with swelling of the right maxillary region, cutaneous vulnus excoriation of superior labial, vulnus laceratum of gingival region 12 to 21 (maxillary right lateral incisor to left central incisor), dental avulsion of tooth 12 (maxillary right lateral incisor) and 11 (maxillary right central incisor) with buccal loss, dentin fracture of tooth 21 and horizontally impacted 38 tooth of class IIB figure 2. Debridement and suture were then done, followed by replantation for tooth 11 and restoration for tooth 21 . Subsequently, implant placement was planned for tooth 12 with an autograft taken from the operated area of tooth 38 (mandibular left third molar).

Two months after trauma, an implant placement with $(\varnothing 4 \mathrm{~mm} \times 11.5 \mathrm{~mm})$-sized implant was done in region 12. The autograft was harvested from the cortical bone covering the dental crown 38 with the use of a bone collector bur. The harvested graft was then applied to the dehiscence-type defect $(4 \times 6 \mathrm{~mm}$ in size) next to the buccal of tooth 12 implant figure 3 . The graft surface was covered with PRF membrane and titanium mesh. The operated area was tightly sutured but not strained, followed by the extraction of tooth 38 .

Three months after the implant placement, titanium mesh was removed while healing abutment was placed. A $2 \mathrm{~mm}$-thick bone formation appeared in the buccal region of implant 12 to the margin of implant crestal. The implant was stable
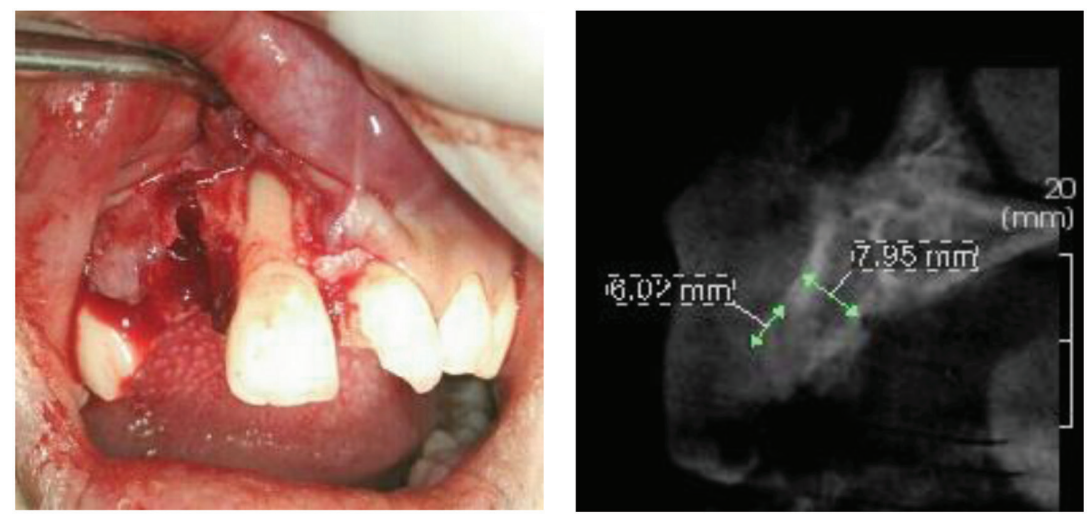

Figure 1 Condition $\mathrm{H}+0$ after accident shows defective socket of tooth 12 with $6 \mathrm{~mm}$ buccal bone loss

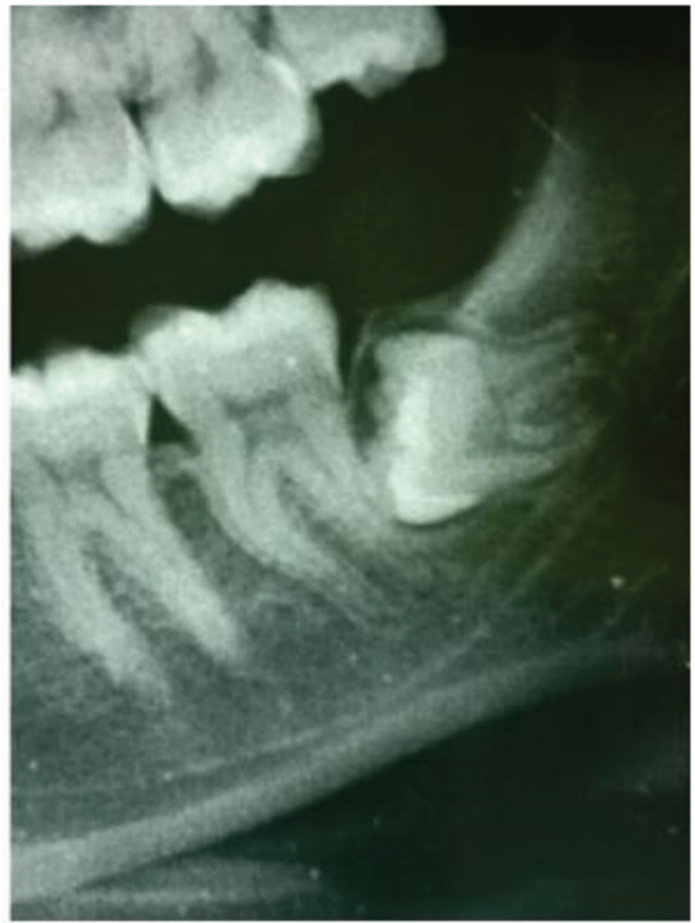

Figure 2 Horizontally impacted tooth 12 of IIB requires cortical bone reduction during removal

and no complications occurred. The procedures were completed with a restoration in the following 2 weeks.

\section{Case 2}

A 19 years old woman came with a failed intentionally dental replant of tooth 22 and intended for replacement. A 1-month periapical radiograph examination after replantation showed a loss of alveolar bone structure in the cervix and around tooth due to resorption figure 4 . Bone mapping indicated insufficient bone width for implant placement.

The graft was harvested from the cortical bone of impacted tooth 48 buccal region with the use of a bone collector figure 5. Once the implant placement was completed, the odontectomy procedures for tooth 48 were applied.

Implant surgery $(\varnothing 3.5 \mathrm{~mm} \times 13.5 \mathrm{~mm})$ was exercised under Guided Bone Regeneration (GBR) procedures using autograft, PRF membrane and titanium mesh-assisted graft fixation. Following the implant placement, defect of the missing bone was clearly visible in the labial area with $\pm 3 \times 7 \mathrm{~mm}$ in size figure $6 \mathrm{~A}$. The bone defect was filled with the autograft to close the crestal dehiscence figure $6 \mathrm{~B}$.

The second surgery was done 4 months later. It appeared that the labial defect area was not found and replaced with a decent $\pm 2 \mathrm{~mm}$-thick bone as high as the implant crestal border figure $6 \mathrm{C}$, 

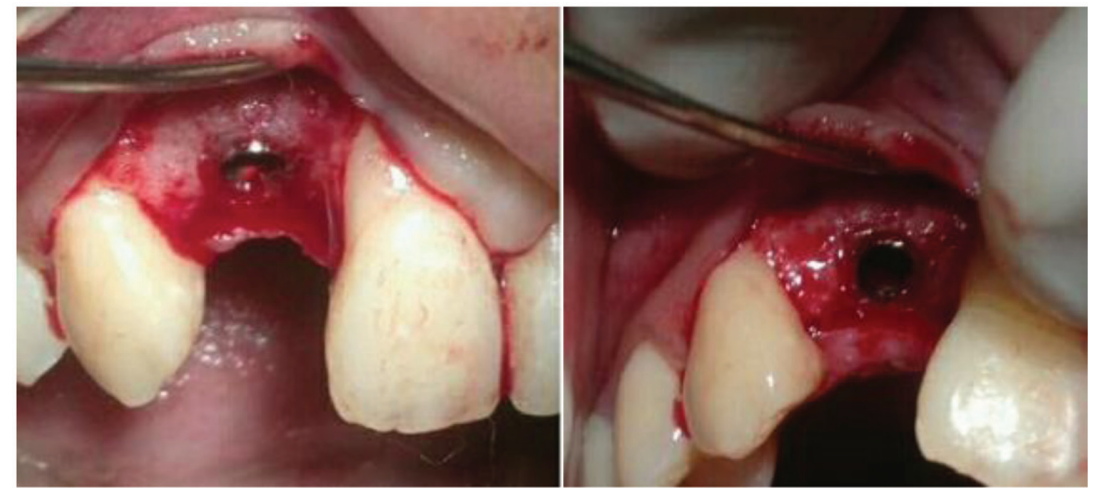

Figure 3 Condition $\mathrm{H}+3$ months after implant placement and bone augmentation shows the formation of new bone in the buccal part of tooth 12 implant

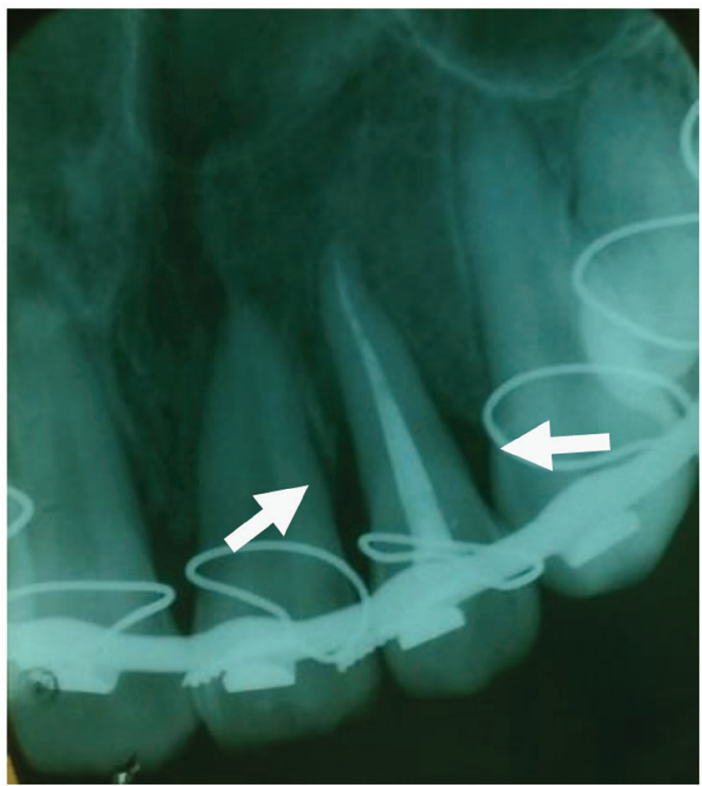

Figure 4 Radiograph examination done 1 month after replantation shows the loss of alveolar bone structure
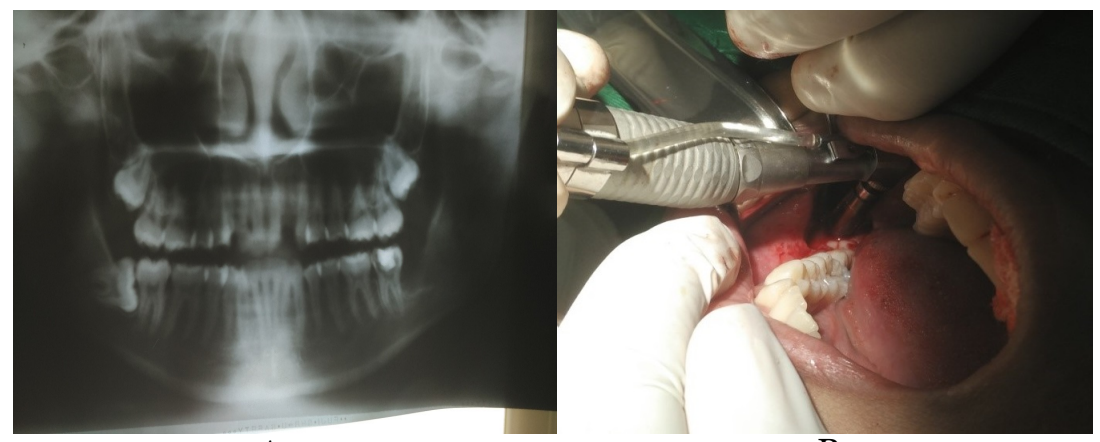

A

B

Figure 5 A. Horizontally impacted tooth 48 of IIA requires cortical bone reduction during removal, $\mathrm{B}$. Autograft harvest with the bone collector of impacted tooth 48 buccal region without clinical or radiographic peri-implantitis markers. A week after the placement of healing abutment, a good emergence profile appeared. The procedures continued with abutment placement and restoration with the dental crown.

\section{Discussion}

The aforementioned cases exhibited a successful augmentation with odontectomy bone-derived autografts. Autograft was chosen for the cases given its abilities for osteogenesis, osteoconduction, and osteoinduction, making it the best graft at present. ${ }^{5}$ Autograft contains osteoprogenitor cells that differentiate into osteoblasts. Autograft also contains a number of growth factors, such as Transforming Growth Factor (TGF) and Fibroblast Growth Factor (FGF), which stimulate blood vessel formation from the host bone to graft, insulin like growth factor 1 (IGF-1) and 2 (IGF-2) with crucial role in the anabolic phase of tissue growth, Bone Morphogenetic Protein (BMP) which is capable of enhancing the ability of cells to form bone through osteoinduction and Vascular Endothelial Growth Factor (VEGF) that initiates the formation of new blood vessels. Autograft also works as a good scaffold for migration and attachment of bone cells and provides structural support for cell growth and division, making autograft the ideal trigger for faster and measurable bone growth. ${ }^{1,7}$ In dental implants, autografts can be harvested from several intraoral areas, such as the mandibular angle, chin, lateral ramus, torus and implant preparation areas. ${ }^{2}$ In addition, autograft can also be harvested from odontectomy bone with advantages such as no discarded bone and no morbidity in normal anatomy. ${ }^{8}$ In general, the areas are grouped into symphysis and ramus. The mandibular symphysis allows corticocancellous graft with more than $1 \mathrm{~cm}^{3}$ in size. It is easy to obtain and likely to get a thick block of graft. However, the patients are mostly concerned with the cosmetic effects of autograft harvest in the symphysis. As a result, it restricts the amount of graft to harvest without harming the patient's cosmetics. In contrast to graft harvesting from the mandibular ramus, the patients are safer from the autograft harvest post cosmetic effects. The graft harvested from the ramus area is generally thinner, less than $1 \mathrm{~cm}^{3}$ in size, cortical and more difficult to obtain. ${ }^{1}$ In this case, the graft was harvested from the odontectomy bone of the impacted third molar in the mandibular ramus region. 


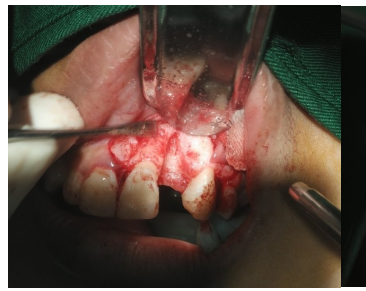

A

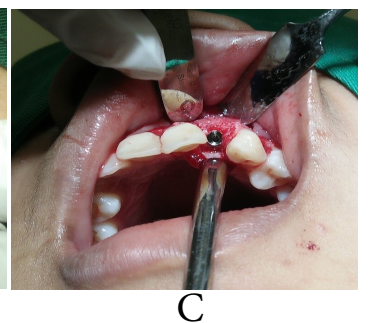

B

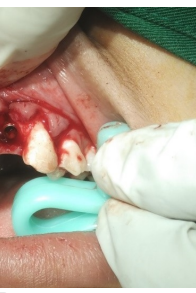

C

Figure 6 A. Wide buccal defect appeared in tooth 21 region, B. Dehiscencetype defect was distinct after implant placement in tooth 22 region, autograft harvest from buccal region of tooth 48 was done. PRF was applied and titanium mesh was used, C. Control done 4 months after implant placement shows adequate thickness of labial bone for implant support

Deeb et $\mathrm{al}^{8}{ }^{8}$ reported the extraction of an impacted third molar along with block-resulting autograft harvest for horizontal defect augmentation..$^{8,9}$ Need-based autograft can be harvested in blocks or particles. Grafts in blocks are structurally stable and more resistant to resorption. Grafts can be harvested from cortical and cancellous bones. The cortical graft is more resistant to resorption, while the cancellous graft allows faster vascular growth. ${ }^{1}$ In this case, the required graft was in particles, demanding a modified technique. Reduction of impacted buccal cortical bone was done with a bone collector bur to obtain a particle-shaped graft material.

Autograft harvest often resulted in triggering defects in other healthy regions. ${ }^{5}$ This case showed that autograft can also be harvested from the operated area of impacted third molar to minimize unnecessary defects. The cortical bone, which is commonly discarded during odontectomy, may serve as a graft material.

\section{Conclusion}

This case exhibited that the autograft from the operated area of impacted third molar resulted in satisfactory outcomes in the implant placement along with bone augmentation under the GBR procedures. The operated area of impacted third molar was considered an ideal alternative for donor sites for patients who needed bone grafts and third

molar extraction. The procedures provided multiple benefits to the patients and reduced possibility for unnecessary defects in the donor areas.

\section{Acknowledgment}

The government of the study country and the World Health Organization did not influence this analysis nor the decision to publish these findings. The study did not receive any financial support.

\section{Conflict of Interest}

The authors report no conflict of interest.

\section{References}

1. Misch CE. Contemporary Implant Dentistry 3rd ed. St Louis: Elsevier; 2008.

2. Levine RA, Manji A, Faucher J, et al. Use of titanium mesh in implant site development for restorative-driven implant placement: case report. Compend 2014;35: 264-273.

3. Cortese A, Pantaleo G, Amato M, et al. Platelet-rich Fibrin (PRF) in implants dentistry in combination with new bone regenerative flapless technique: evolution in the technique and final results. Open Med 2017;12: 24-32.

4. Joseph VR, Sam G, Amol NV. Clinical Evaluation of autologous platelet-rich fibrin in horizontal alveolar bony defects. J Clin Diagn Res 2014;8: ZC43-47.

5. Sukumar S, Drizhal I. Bone graft in periodontal therapy. Acta Med (Hradec Kralove) 2008;51: 203-207.

6. Santosh P. Impacted mandibular third molars: review of literature and a proposal of a combined clinical and radiological classification. Ann Med Health Sci Res 2015;5: 229-234.

7. Toffler M. Guided Bone Regeneration (GBR) using cortical bone pins in combination with Leukocyte and Platelet-rich Fibrin (L-PRF). Compend 2014;35: 192-198.

8. Deeb GR, Laskin DM, Deeb JG. Simultaneous impacted third molar extraction and lateral ramus block graft harvest for horizontal ridge augmentation: a case series. J Oral Maxillofac Surg 2017;75: 509-513.

9. Anton, Rahajoe PS, Dwirahardjo B. Sandwich Bone Augmentation (SBA) in immediate implant placement post dentoalveolar trauma: a case report. J Dentomaxillofac Sci 2017;2: 197-200.

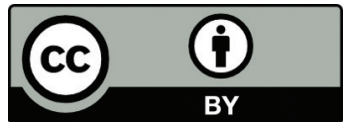

This work is licensed under a Creative Commons Attribution 